Pesq. Vet. Bras. 37(10):1049-1056, outubro 2017 DOI: $10.1590 / \mathrm{S} 0100-736 \mathrm{X} 2017001000002$

\title{
Soluções de óxido de zinco e de nitrato de prata como alternativa para antissepsia de tetos de bovinos (teste in situ) ${ }^{1}$
}

\author{
Ana Paula Pereira Alves ${ }^{2 *}$, Vinicius da Silva Amorim ${ }^{3}$, Dielson da Silva Vieira ${ }^{4}$, Rodolfo \\ de Moraes Peixoto ${ }^{5}$, Helinando Pequeno de Oliveira ${ }^{6}$ e Mateus Matiuzzi da Costa $^{2}$
}

\begin{abstract}
Alves A.P.P., Amorim V.S., Vieira D.S., Peixoto R.M., Oliveira H.P. \& Costa M.M. 2017. [Solutions of Zinc oxide and silver nitrate as an alternative to bovine udder antisepsis.] Soluções de óxido de zinco e de nitrato de prata como alternativa para antissepsia de tetos de bovinos. Pesquisa Veterinária Brasileira 37(10):1049-1056. Curso de Pós-Graduação em Ciências Veterinárias no Semiárido, Universidade Federal do Vale do São Francisco, Rodovia BR-407, Lote 543, PSNC-C1, s/n, Petrolina, PE 56300-990, Brasil. E-mail: appatec@hotmail.com

This study aimed to analyze the zinc oxide and silver nitrate solutions as an alternative antiseptic for cow teats (in situ), considering the lack in the literature about these compounds uses in mastitis prophylaxis. First microdilution tests med and MBC (Minimal Bactericidal Concentration were perfor in order to determine the antimicrobial activity of zinc oxide and silver nitrate solutions over 30 Staphylococcus spp. isolates, obtained from cows with mastitis. All strains tested showed sensitivity to both solutions, but the silver nitrate solution had lower MBC values $(3,05$ to $97,65 \mathrm{ug} / \mathrm{ml})$ compared with zinc oxide solution MBCs $(97,65$ to $6,250 \mathrm{ug} / \mathrm{ml})$. Subsequently, the antiseptic teat tests were conducted (in situ) by immersing the teats in same antimicrobial solutions tested in the first experiment. Therefore, 40 teats were used $(n=40)$ originating from slaughtered cows were divided into 4 groups of 10 teats, to test test zinc oxide $3 \%(30 \mathrm{mg} / \mathrm{mL})$ and silver nitrate $1 \%(10 \mathrm{mg} / \mathrm{mL})$ solutions and their respective controls. The teats were submitted to mesophilic count on the teat surface $\left(\mathrm{CFU} / \mathrm{cm}^{2}\right)$ before and after immersion in tested solutions. As a result, all the solutions (zinc oxide and silver nitrate) had a significant reduction in $\mathrm{CFU} / \mathrm{cm}^{2}$ until 60 minutes after immersion (M 0' to $60 \mathrm{M}$ ). Silver nitrate solution showed a reduction of $\mathrm{CFU} / \mathrm{cm}^{2}$ significantly higher compared to the group treated with zinc oxide solution. These results validate the potential use of zinc oxide and silver nitrate solutions in dairy cows as a pre- and post-dipping antiseptic.

INDEX TERMS: Teats antisepsis, zinc oxide, silver nitrate, cattle.
\end{abstract}

\footnotetext{
${ }^{1}$ Recebido em 26 de janeiro de 2016.

Aceito para publicação em 14 de fevereiro de 2017.

Pesquisa de Mestrado do primeiro autor.

${ }^{2}$ Programa de Pós-Graduação em Ciências Veterinárias no Semiárido, Universidade Federal do Vale do São Francisco (Univasf), Rod. BR-407, lote 543, PSNC-C1 s/n, Petrolina, PE 56300-990, Brasil. E-mail: mmatiuzzi @hotmail.com, *Autor para correspondência: appatec@hotmail.com

${ }^{3}$ Graduação em Medicina Veterinária, Univasf, Rod. BR-407, lote 543, PSNC-C1 s/n, Petrolina, PE 56300-990, Brasil. E-mail: vinicius_amorim10@ hotmail.com

${ }^{4}$ Programa de Pós-Graduação em Ciência Animal Tropical, Universidade Federal Rural de Pernambuco (UFRPE), Campus Dois Irmãos, Recife-PE 52171-900, Brasil. E-mail: dielson.vieira@ig.com.br

${ }^{5}$ Colegiado de Zootecnia, IFE Sertão Pernambucano, BR-235, Km 22, PSNC-N4, Zona Rural, Petrolina-PE 56302970, Brasil. E-mail: rodolfo_ medvet@hotmail.com

${ }^{6}$ Pós-Graduação em Ciência dos Materiais, Univasf, Av. Antônio Carlos Magalhães 510, Santo Antônio, Juazeiro, BA 48902-300, Brasil. E-mail: helinando@gmail.com
}

RESUMO.- Este trabalho teve como objetivo analisar o potencial das soluções de óxido de zinco e de nitrato de prata como alternativa para antissepsia de tetos de bovinos (in situ), considerando a escassez de literatura a respeito do uso destes compostos na profilaxia de mastites. Primeiramente foram realizados ensaios de microdiluição e CBM (Concentração Bactericida Mínima) a fim de verificar a atividade antimicrobiana das soluções de óxido de zinco e de nitrato de prata sobre 30 isolados de Staphylococcus spp., obtidos de casos de mastite. Todos os isolados apresentaram sensibilidade às duas soluções testadas, mas a solução de nitrato de prata apresentou menores valores de CBMs $(3,05$ a $97,65 \mu \mathrm{g} / \mathrm{mL})$, quando comparada as CBMs da solução de óxido de zinco $(97,65$ a $6.250 \mu \mathrm{g} / \mathrm{mL})$. Posteriormente, foram conduzidos os ensaios de antissepsia 
dos tetos (in situ) através da imersão dos mesmos nas soluções antimicrobianas testadas. Para isso, foram utilizados 40 tetos $(n=40)$ oriundos de vacas abatidas, os quais foram divididos em 4 grupos de 10 tetos, destinados ao teste das solução de óxido de zinco a $3 \%(30 \mathrm{mg} / \mathrm{mL})$, de nitrato e prata $1 \%(10 \mathrm{mg} / \mathrm{mL})$ e seus respectivos controles. Os tetos foram submetidos à contagem de microrganismos mesófilos na superfície dos tetos $\left(\mathrm{UFC} / \mathrm{cm}^{2}\right)$ antes e após a imersão nas soluções testadas. Como resultado, todas as soluções (de óxido de zinco e de nitrato de prata) apresentaram significativa redução de $\mathrm{UFC} / \mathrm{cm}^{2}$ até aos 60 minutos após a imersão (M 0' a M 60'). A solução de nitrato de prata apresentou redução de $\mathrm{UFC} / \mathrm{cm}^{2}$ significativamente maior, quando comparado ao grupo testado com solução de óxido de zinco. Tais resultados validam o potencial das soluções de óxido de zinco e nitrato de prata para utilização no pré e pós-dipping em vacas leiteiras.

TERMOS DE INDEXAÇÃO: Antissepsia de tetos, óxido e zinco, nitrato de prata, bovinos.

\section{INTRODUÇÃO}

No ano de 2014, o efetivo total do rebanho de bovinos no Brasil foi de 212,34 milhões de cabeças, desse total 10,9\% corresponde a vacas ordenhadas. Este índice coloca o país na segunda posição mundial em relação ao efetivo de vacas ordenhadas, ficando atrás apenas da Î́ndia (IBGE 2014).

Tais índices expressam a importância que a pecuária leiteira adquiriu no país, motivada pelo seu desempenho econômico, pela geração de empregos permanentes (Fundação Banco do Brasil 2010), e ainda pela importância do leite na alimentação humana, devido à sua riqueza em nutrientes proporcionando um conjunto abrangente de benefícios para a saúde (Gomes et al. 2008).

Apesar do Brasil apresentar destaque na pecuária leiteira mundial, o leite oriundo de algumas criações continua a apresentar baixa qualidade microbiológica tendo em vista as más condições higiênico-sanitárias; o estado de saúde dos animais e cuidados inadequados com utensílios e equipamentos utilizados nos procedimentos de ordenha (Simões \& Oliveira 2012). Este cenário proporciona uma prevalência acentuada da mastite no rebanho, enfermidade de natureza plurietiológica, que compromete o desempenho da atividade leiteira através de significativas reduções na produção e qualidade do leite, perdas pelo descarte de animais e custos com o tratamento (Radostits et al. 2002, Contreras et al. 2007).

O plano de controle e prevenção da mastite é provido de diversas estratégias, tais como higienização do ambiente; dos equipamentos e a lavagem do úbere antes da ordenha, as quais reduzem o número de microrganismos patogênicos (Quinn et al. 2005). Contudo, a antissepsia de tetos antes (pré-dipping) e após (pós-dipping) a ordenha constitui-se das mais eficazes estratégias de controle da mastite contagiosa e ambiental, já que a pele do teto, além constar uma microbiota intrínseca, é contaminado com bactérias oriundas do ambiente (Fonseca \& Santos 2007, Coser et al. 2012).

Um número limitado de antissépticos químicos pode ser usado na lavagem de tetos, tais como, soluções a base de cloro, iodóforos, compostos quaternários de amônia. A limitação está associada a uma série de exigências que devem ser cumpridas para seu uso com eficácia e segurança (Pedrini \& Margatho 2003). Além disso, a emergência de cepas bacterianas resistentes a desinfetantes utilizados em pré e pós dipping podem dificultar programas de prevenção e controle de mastite nos rebanhos leiteiros. Tais pressupostos são embasados na existência de variações no perfil de sensibilidade e resistência dos microrganismos a alguns compostos antimicrobianos já utilizados em procedimentos de antissepsia de tetos (Medeiros 2008, Ramalho et al. 2012), reascendendo a necessidade de busca contínua por novos fármacos para esta finalidade (Rocha et al. 2011).

Partindo dessa premissa, alguns métodos alternativos de tratamento e prevenção contra mastite vêm sendo amplamente estudados nos últimos anos (Andrade 2010, Yokoia 2010, Faccin 2013). Porém, todos estes estudos partem de princípios ativos de materiais orgânicos, como por exemplo, muco de escargots Achatina spp.; extrato de própolis e da planta aroeira.

As altas e amplas atividades antimicrobianas dos sais inorgânicos foram documentas, e vem sendo utilizadas em procedimentos terapêuticos na medicina humana e veterinária (Spinosa et al. 2006, Batistuzzo et al. 2011, Anvisa 2012). 0 óxido de zinco (ZnO) caracterizou-se como um importante material industrial ao longo do tempo e atualmente vem sendo objeto de interesse considerável, por apresentar uma combinação de propriedades físicas, químicas e biológicas (ação antibacteriana) (Feltrin 2010). 0 nitrato de prata $\left(\mathrm{AgNO}_{3}\right)$, tem sido utilizado durante séculos como agente antimicrobiano, mas o uso deste, diminuiu drasticamente quando os antibióticos foram introduzidos nas práticas médicas (Atiyeh et al. 2007).

Deste modo, este ensaio teve como objetivo analisar o potencial das soluções de óxido de zinco e de nitrato de prata como alternativa para antissepsia de tetos de bovinos, cujas formulações ainda não tinham sido testadas para esta finalidade.

\section{MATERIAL E METÓDOS}

Local de execução. 0 experimento foi executado no Laboratório de Microbiologia e Imunologia Animal da Universidade Federal do Vale do São Francisco, localizado no Campus de Ciências Agrárias, no município de Petrolina no estado de Pernambuco, no período de outubro de 2014 a novembro de 2015.

Determinação da atividade antimicrobiana do óxido de zinco e do nitrato de prata contra Stahylococcus spp. obtidos de mastite bovina, através da técnica de Microdiluição e Concentração Bactericida Mínima

Obtenção das amostras (dos isolados). Foram utilizados 17 isolados de Staphylococcus aureus e 13 isolados de Staphylococcus coagulase positiva (SCP), todos obtidos da bacterioteca do laboratório de Microbiologia e Imunologia Animal, resultantes de experimentos executados por Krewer et al. (2014), que recuperou estes microrganismos a partir do leite de vacas com mastite clínica e subclínica oriundas de propriedades dos estados da Bahia e de Pernambuco, sendo localizadas no Vale Submédio São Francisco e no Agreste Pernambucano. 
Obtenção e preparo dos agentes antimicrobianos. Todos os isolados bacterianos foram testados frente aos dois compostos inorgânicos: óxido de zinco $(\mathrm{ZnO})$ e nitrato de prata $\left(\mathrm{AgNO}_{3}\right)$, ambos provenientes do Laboratório de Ciências dos Materiais da UNIVASF. Antes da sua utilização nos ensaios de microdiluição e CBM, as soluções do óxido de zinco e de nitrato de prata foram preparadas a partir de água destilada esterilizadas a uma concentração final de $25 \mathrm{mg} / \mathrm{mL}$.

Microdiluição e CBM. A atividade antimicrobiana do óxido de zinco e do nitrato de prata foi determinada utilizando o método de microdiluição, baseado no documento M7-A6 do Clinical and Laboratory Standards Institute (CLSI 2015), com pequenas modificações.

Após o processo de replicação dos 30 isolados, deu-se início ao procedimento de microdiluição, ao realizar a técnica padrão de turvação a 0,5 na escala de Mac Farland ( 1 x $\left.10^{8} \mathrm{UFC} / \mathrm{mL}\right)$, utilizando-se solução salina a 0,85\%. Depois, adicionou-se $0,1 \mathrm{~mL}$ da suspensão turva (solução salina com isolados de Staphylococcus spp.) a 9,9 ml de caldo Mueller Hinton (MH) em tubos de ensaio. Para cada grupo do antimicrobiano testado (óxido de zinco e nitrato de prata), foram produzidos 30 tubos de ensaios contendo $10 \mathrm{~mL}$ da solução composta por $9,9 \mathrm{~mL}$ de caldo $\mathrm{MH}$ adicionado de 0,1 mL da suspensão de Staphylococcus spp.

Logo após, procedeu-se com a microdiluição em microplacas na capela de fluxo laminar. Inicialmente, com o auxílio da micropipeta multicanal, coloca-se $200 \mu$ de caldo $\mathrm{MH}$, puro e estéril em cada poço da microplaca, procedendo-se logo em seguida com a diluição do óxido de zinco e nitrato de prata, colocando-se $200 \mu \mathrm{l}$ dos mesmos nos primeiros poços, seguindo-se uma diluição de 1:2 e descartando-se os últimos $200 \mu \mathrm{l}$. Assim, obtiveram-se diferentes concentrações ao longo dos oito poços das microplacas: $1^{\text {a }}-12.500 \mu \mathrm{g} / \mathrm{mL} ; 2^{\underline{a}-} 6.250 \mu \mathrm{g} / \mathrm{mL} ; 3^{\mathrm{a}}-3.125 \mu \mathrm{g} / \mathrm{mL} ; 4^{\mathrm{a}}-1.562,5$ $\mu \mathrm{g} / \mathrm{mL} ; 5$ a- $781,2 \mu \mathrm{g} / \mathrm{mL} ; 6$ a- 390,6 $\mu \mathrm{g} / \mathrm{mL} ; 7 \underline{a}-195,3 \mu \mathrm{g} / \mathrm{mL}$; $8^{\text {a }}-97,6 \mu \mathrm{g} / \mathrm{mL}$. Como todos os isolados exibiram sensibilidade até a 8a concentração $(97,6 \mu \mathrm{g} / \mathrm{mL})$ para a solução de nitrato de prata, procedeu-se a nova microdiluição até a concentração de 3,05 $\mu \mathrm{g} / \mathrm{mL}$. Em seguida, adicionou-se $10 \mu \mathrm{L}$ de caldo MH contendo os micro-organismos em cada poço. As microplacas também continham os poços de controles positivo e negativo. No último colocou-se apenas o caldo $\mathrm{MH}$, sem adição dos antimicrobianos testados (óxido de zinco e nitrato de prata) e sem a solução com os Staphylococcus spp., afim de garantir a esterilidade do meio ao longo do teste. Nos poços de controle positivo, encontravam-se o caldo MH inoculado com os isolados de Staphylococcus spp. utilizados, afim de verificar a viabilidade dos isolados. Em seguida, as microplacas foram encaminhadas a estufa, sendo incubadas a $37^{\circ} \mathrm{C}$ por 24 horas.

Decorridas as 24 horas, iniciou-se o teste de CBM (Concentração Bactericida Mínima), com o auxílio de um replicador de microplacas, inoculou-se o conteúdo de cada poço da microplaca em placas de petri contendo MH Agar. Estas placas foram incubadas por 24 horas a $37^{\circ} \mathrm{C}$. Decorrido esse tempo, foi efetuada a leitura das placas. 0 poço na menor concentração que não foi observado nenhum crescimento bacteriano é considerada a Concentração Bactericida Mínima (CBM). Todas as amostras foram testadas em triplicata (CLSI 2015). Com o objetivo de comparar as CBMs obtidas frente as soluções de óxido de zinco e de nitrato de prata, empregou-se o teste de Wilcoxon.

Teste das soluções de óxido de zinco e de nitrato de prata como antissépticos de tetos bovinos (teste in situ)

Delineamento experimental e obtenção dos tetos. Foram utilizados um número amostral de 40 tetos de vaca $(n=40)$, sendo este total divido em 04 grupos de 10 tetos. Um (01) grupo foi destinado ao teste com as soluções de óxido de zinco à 3\% (30mg/
$\mathrm{mL}$ ), denominado Tratamento Óxido de Zinco, sendo paralelamente testado com outro grupo de tetos $(n=10)$, denominado Tratamento Controle óxido de zinco, utilizando a solução controle a base de dicloroisocianurato de sódio anidro, preparada conforme recomendação do fabricante. Da mesma forma, outro grupo de tetos foi destinado ao teste com soluções de nitrato de prata à $1 \%$ (10mg/mL), denominado Tratamento Nitrato de Prata, sendo paralelamente testado com outro grupo de tetos $(n=10)$, denominado Tratamento Controle nitrato de prata, utilizando a solução controle a base de dicloroisocianurato de sódio anidro. Os tetos destinados aos tratamentos experimentais (óxido de zinco ou nitrato de prata) foram paralelamente testados com outros tetos como controle, sendo ambos oriundos de um mesmo úbere, com o propósito de igualar as condições do ensaio.

Os 40 tetos $(n=40)$ foram obtidos a partir de vacas abatidas no abatedouro municipal de Petrolina-PE. Logo após o abate, quando ainda as vacas eram encontradas na linha de abate, os tetos foram retirados e imediatamente acondicionados em sacos plásticos estéreis, e devidamente lacrados foram colocados numa caixa isotérmica com gelo. Em seguida os tetos foram encaminhados até o laboratório de Imunologia e Microbiologia Animal da UNIVASF, dando início ao procedimento de higienização dos tetos utilizando soluções de óxido de zinco e nitrato de prata através do método de imersão.

Realização de higienização dos tetos utilizando soluções de óxido de zinco e nitrato de prata através do método de imersão ou toalhas (teste in situ). Primeiramente, foi marcado o local de coleta dos espécimes clínicos no teto, demarcando uma área de $4 \mathrm{~cm}^{2}$ na superfície da região mediana do teto com o auxílio de um molde de papel cartolina esterilizado. Para coleta a coleta dos espécimes clínicos foram realizados quatro movimentos cruzados usando um swab bacteriológico estéril (Finger 2001).

Para avaliação do efeito das soluções dos compostos inorgânicos óxido de zinco e nitrato de prata, foi realizado um (01) swab antes da imersão dos tetos nas soluções, sendo denominado como Momento 0'. Em seguida, foi procedida a imersão dos tetos nas soluções antimicrobianas, por um período de 30 segundos, sendo este considerado o tempo mínimo de contato estabelecido com a solução sanitizante (Brito et al. 2000, Amaral et al. 2004). Dez (10) minutos após a imersão, procedeu-se realização de outro swab na mesma área delimitada, sendo denominado Momento 10'. Mais dois (02) swabs foram realizados na área delimitada na superfície do teto, aos 30 minutos e 60 minutos após a imersão, períodos denominados como Momento 30' e Momento 60', respectivamente.

Realização de plaqueamento em profundidade ou Pour Plate. Após a coleta, cada "swab" foi acondicionado imediatamente em um tubo de ensaio esterilizado, contendo água peptonada. A partir deste tubo, realizaram-se diluições sucessivas até $10^{-4} \mathrm{em}$ tubos de ensaio contendo caldo Muller Hinton. Em seguida, próximo ao bico de bunsen, inoculou-se $1 \mathrm{~mL}$ de cada diluição em placas de petri estéreis e vazais, e em seguida, verteu-se $15 \mathrm{~mL}$ de meio PCA (Contagem Padrão em Placa) nas placas inoculadas, misturando o meio com o inóculo através de movimentos circulares. Aguardou-se a completa solidificação do meio de cultura, até que as placas foram encaminhadas até a estufa, a $37^{\circ} \mathrm{C}$ por um período de 48 horas. Os testes foram conduzidos em duplicata (Silva et al. 2007).

Contagem das unidades formadoras de colônias (UFC) e cálculo dos resultados. Após as 48 horas de incubação, as placas foram submetidas a contagem das colônias com o auxílio da lupa de um contador de colônias. Para contagem, foram selecionadas placas sem espalhamento, e para efeito do cálculo foram consideradas as placas com número de 30 a 300 colônias. Para o cálculo das unidades formadoras de colônias, foram consideradas 
a média aritmética das contagem de colônias das placas em duplicata e multiplicou-se pelo inverso das diluições. Também, foi devidamente procedida a transformação dos valores de UFC para $\mathrm{UFC} / \mathrm{cm}^{2}$, após considerar que as amostras foram preparadas pela técnica de esfregaço de superfície (Silva et al. 2007).

Análise estatística dos dados. A ausência de normalidade dos dados foi confirmada pelo teste de Kolmogorov-Smirnov. Dessa forma, os valores obtidos para UFC/ $\mathrm{cm}^{2}$ foram submetidos à transformação logarítmica de base $10\left(\log _{10}\right)$ para análise estatística, e a função antilogarítmica para apresentação dos resultados. Os valores obtidos de UFC/ $\mathrm{cm}^{2}$ foram comparados entre os tratamentos, utilizando-se a análise de variância para amostras independentes e entre os momentos experimentais pela análise de variância para medidas repetidas. Empregou-se o teste de Bonferroni para comparação das médias. Para análise dos dados, foi utilizado o programa Statistical Package for the Social Sciences (SPSS) versão 20.0 para Windows.

\section{RESULTADOS E DISCUSSÃO}

\section{Atividade antimicrobiana da solução de óxido de zinco}

Houve diferença estatística significativa $(\mathrm{p}<0.01)$ quando comparou-se os valores de CBMs das soluções de óxido com as CBMs das soluções de nitrato de prata. Todos os isolados de Staphylococcus spp. testados apresentaram sensibilidade ao óxido de zinco, mas com uma distribuição desuniforme dos valores das CBMs. Tais isolados exibiram uma variação de 97,65 a $6.250 \mu \mathrm{g} / \mathrm{mL}$, sendo que $43,3 \%$ dos mesmos foram sensíveis a menor concentração $(97,65$ $\mu \mathrm{g} / \mathrm{mL}$ ) (Fig.1). A média e a mediana obtidas dos valores das CBMs da solução do óxido de zinco foram 1.396,48 $\mu \mathrm{g} /$ $\mathrm{mL}$ e $292,96 \mu \mathrm{g} / \mathrm{mL}$, respectivamente.

A partir da década de 90, alguns pesquisadores intensificaram as investigações a respeito do potencial de óxido de zinco como antimicrobiano, certificando que Stapylococcus aureus exibia uma alta sensibilidade ao óxido de zinco, o que não foi demonstrado para a espécie Escherichia coli. (Sawai et al. 1995). Soderberg e colaboradores, em 1990, verificaram que as bactérias gram positivas são mais susceptíveis ao óxido de zinco, comparada as gram negativas. Estas não foram inibidas mesmo sendo submetidas a altas concentrações, ao tempo em que isolados de Staphylococcus epidermidis exibiram uma notável sensibilidade ao $\mathrm{ZnO}$.

Alguns pesquisadores tentaram elucidar o mecanismo de ação do ZnO. Um dos pontos a serem considerados é o fato do $\mathrm{ZnO}$ ser altamente insolúvel em água, mas exibe maior solubilidade em condições ácidas. Nessa situação, o $\mathrm{ZnO}$ dissocia-se liberando $\mathrm{Zn}^{+2}$, o qual pode exercer funções bactericidas, pois o efeito antimicrobiano dos metais pesados, geralmente, está associodo a sua forma iônica, assim como ocorre com o elemento prata (Ag). Alguns autores associam este príncipio ao efeito resultante da aplicação do óxido de zinco na prevenção de diarreias neonatais em suínos. Contudo, existem expeculações de que a própria molécula de óxido de zinco $(\mathrm{ZnO})$ tem um efeito sobre o crescimento bacteriano (Silver 1996, Liedtke \& Vahjen 2012).

Sawai et al. (1998), Sawai (2003) propuseram que a geração de peróxido de hidrogênio $\left(\mathrm{H}_{2} \mathrm{O}_{2}\right)$, a partir da molécula de $\mathrm{ZnO}$, pode ser o fator principal da atividade antimicrobiana do óxido de zinco. Os mesmos autores afirmaram que a taxa de dissociação do óxido de zinco em água é muito baixa, logo a formação de $\mathrm{Zn}^{+2}$ pouco influencia no mecanismo de ação do óxido de zinco. Para confirmar esta hipótese, os mesmos pesquisadores utilizaram soluções de $\mathrm{ZnCl}_{2}$ sobre $S$. aureus e E. coli, em uma concentração 10 vezes maior de $\mathrm{Zn}^{+2}$, em relação a quantidade desse íon obtido em soluções de ZnO. No entanto, os íons $\mathrm{Zn}^{+2}$ não apresentaram efeito sobre o crescimento de $E$. coli e $S$. aureus, sugerindo que o contato do pó de $\mathrm{ZnO}$ com célula bacteriana é um fator muito importante. Amornpitoksuk et al. (2011) também verificaram que a atividade antibacteriana do óxido de zinco diminuiu quando dissolvido em solução ácida, devido ao aumento da taxa de dissolução do $\mathrm{ZnO}$.

Com base no exposto acima, prevê-se que o mecanismo de ação verificado neste ensaio é resultado da geração de peróxido de hidrogênio $\left(\mathrm{H}_{2} \mathrm{O}_{2}\right)$, a partir da molécula de $\mathrm{ZnO}$, já que utilizou-se água estéril como solvente na preparação da solução de óxido de zinco.

\section{Atividade antimicrobiana da solução de nitrato de prata}

Os isolados de Staphylococcus spp. também demonstraram sensibilidade à solução do nitrato de prato, com valores de CBM significadamente menores que os valores das CBMs da solução de óxido de zinco $(p<0,01)$, tendo uma variação entre 3,05 a 97,65 $\mu \mathrm{g} / \mathrm{mL}$ (Fig.2). Dos 30 isolados testados, 13 (43,3\%) apresentaram valor de CBM de 24,41 $\mu \mathrm{g} / \mathrm{mL}$ e outros $12(40 \%)$ isolados apresentaram valores

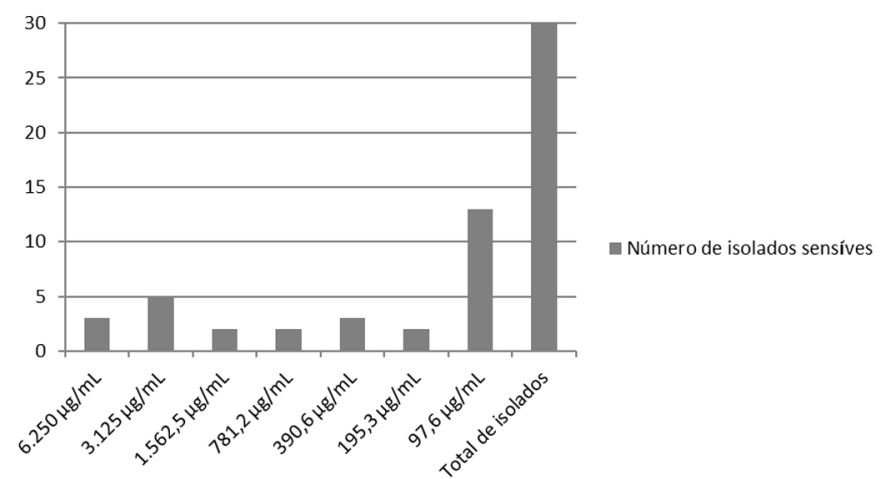

Fig.1. Concentração Bactericida Mínima (CBM) da solução de óxido de zinco sobre isolados de Staphylococcus spp.

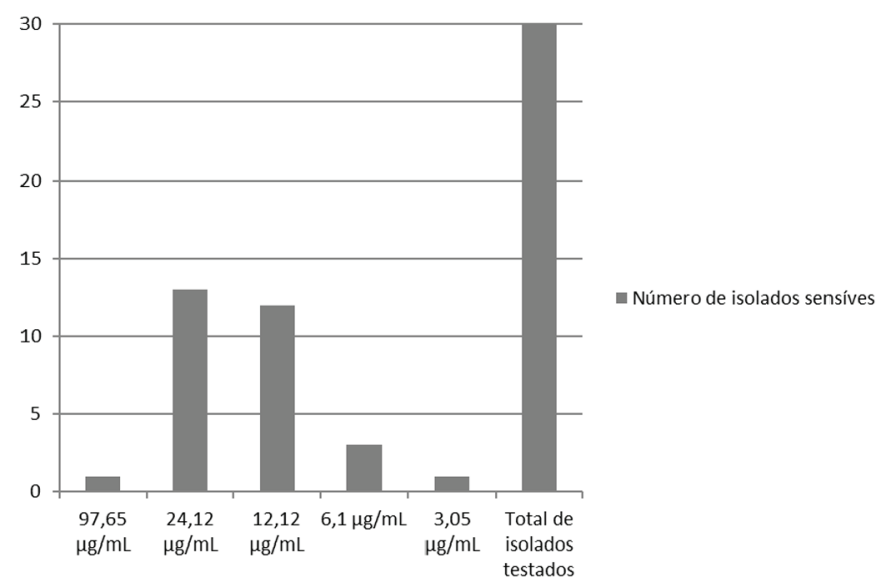

Fig.2. Concentração Bactericida Mínima (CBM) da solução de nitrato de prata sobre isolados de Staphylococcus spp. 
de CBM de 12,29 $\mu \mathrm{g} / \mathrm{mL}$ (Fig.2). A média e a mediana obtidas dos valores das CBMs da solução de nitrato de prata foram 19,42 $\mu \mathrm{g} / \mathrm{mL}$ e 12,20 $\mu \mathrm{g} / \mathrm{mL}$, respectivamente.

A evidência da alta atividade das soluções do nitrato de prata é condizente com os postulados de Atiyeh et al. (2007) ao afirmarem que os sais de prata foram utilizados durante séculos como agentes antimicrobianos e que o uso destes diminuiu drasticamente quando os antibióticos foram introduzidos nas práticas médicas.

O emprego da prata e de seus compostos na medicina se deve à atividade antimicrobiana dos íons $\mathrm{Ag}^{+}$, sendo seu estado elementar $\left(\mathrm{Ag}^{0}\right)$, considerado inerte ou fracamente absorvido por células bacterianas. Por isso, a prata elementar requer ionização em prol de uma eficaz atividade antimicrobiana (Lansdown 2002, Trop et al. 2006, Castellano et al. 2007).

O mecanismo exato de ação da prata sobre os microrganismos ainda não está plenamente elucidado, mas tem sido sugerido com base nas alterações morfológicas e estruturais verificadas nas células bacterianas (Rai et al. 2009).

Segundo alguns autores, os íons de prata se ligam a proteínas teciduais e promove mudanças estruturais na parede celular bacteriana e da membrana nuclear de célula, levando à distorção e à morte (Castellano et al. 2007). Outros estudiosos acrescentam que a prata também se liga ao DNA e RNA bacteriano exercendo desnaturação e inibindo a replicação bacteriana (Lansdown 2002, Atiyeh et al. 2007).

Percival et al. (2005) afirmaram que a ação inibidora da prata decorre, em parte, da sua acumulação dentro do organismo bacteriano e de uma forte interação com grupos tiol presentes em enzimas respiratórias das células bacterianas.

A partir dos pressupostos mecanismos de ação, algumas espécies de bactérias foram documentadas como sensíveis aos compostos de prata, tais como Staphylococcus aureus resistente à meticilina (MRSA) e Enterococos resistentes à vancomicina (Atiyeh et al. 2007). Como também, Pseudomonas aeruginosa, Escherichia coli, Enterobacter cloacae, Proteus vulgaris, Acinetobacter baumannii (Ip et al. 2006), Vibrio cholerae, Staphylococcus flexneri, e Staphylococcus typhimurium (Sarkar et al. 2007).

\section{Teste das soluções de óxido de zinco e de nitrato de pra- ta como antissépticos de tetos bovinos (teste in situ)}

Essa etapa do experimento visou comparar a aplicação da solução de óxido de zinco $3 \%(30 \mathrm{mg} / \mathrm{mL})$ e da solução de nitrato de prata $1 \%(10 \mathrm{mg} / \mathrm{mL})$, com a solução antisséptica comercial já utilizada, à base de dicloroisocianurato de sódio anidro, na lavagem de úbere e tetos e na desinfecção de equipamentos de ordenha. Desta forma, os efeitos dos diferentes tratamentos no procedimento de antissepsia dos tetos estão apresentados no Quadro 1.

Ao observar os resultados no quadro, constata-se que todos os tratamentos foram eficazes no tocante a redução do número UFC $/ \mathrm{cm}^{2}$ da superfície dos tetos, devendo-se fazer algumas considerações.

0 tratamento óxido de zinco foi igualmente eficaz ao seu controle ao longo dos primeiros 30 minutos, diferenciando-se somente aos 60 minutos. Neste último momento, a solução controle teve uma redução $\mathrm{de} \mathrm{UFC} / \mathrm{cm}^{2}$ mais significativa. 0 tratamento nitrato de prata também foi tão eficaz quanto ao seu tratamento controle no decorrer dos 60 minutos, porém apresentou redução significativamente maior aos 10 minutos após a imersão. Estes resultados indicam que as soluções de óxido de zinco e de nitrato de prata conferem proteção antimicrobiana equivalente (até superior) à solução comercial testada.

Comparando os desempenhos entre as soluções experimentais (soluções de óxido de zinco e nitrato de prata), verificou-se que em todos os momentos do ensaio (M 10', M 30 ' e M 60'), o grupo Tratamento Nitrato de Prata diferenciou-se do grupo Tratamento Óxido de Zinco, apresentando uma redução significativamente maior no número de UFC/ $\mathrm{cm}^{2}$.

É importante frisar que os tratamentos Óxido de Zinco e Nitrato de Prata estabilizaram suas atividades antimicrobianas aos 30' e 60' finais, porém, diferenças estatísticas foram observadas do número de $\mathrm{UFC} / \mathrm{cm}^{2}$ reduzidas pela ação do nitrato de prata quando comparado ao óxido de zinco no mesmo período.

Ressaltando a ação da solução nitrato de prata, observou-se que a mesma demonstrou maior atividade antimicrobiana no momento 10' quando comparado ao seu grupo controle e ao Tratamento Óxido de Zinco. Isso reflete uma particularidade da solução de nitrato de prata em reduzir o número de $\mathrm{UFC} / \mathrm{cm}^{2}$ em um menor período de tempo, fato que se apresentaria como uma vantagem no que diz respeito a sua aplicação em procedimentos de pós-dipping. Esta técnica objetiva manter uma proteção do óstio do teto contra a invasão de patógenos ambientais logo após a ordenha, já que se preconiza que somente decorridas 1-2 horas depois da ejeção do leite, o esfíncter volta ao seu estado normal (Langoni 2013).

Apesar da evidência da eficaz redução em número de $\mathrm{UFC} / \mathrm{cm}^{2}$ por parte das soluções de óxido de zinco e nitrato de prata, torna-se necessária a elucidação das mesmas no

Quadro 1. Medianas obtidas para UFC/ $\mathrm{cm}^{2}$ nos diferentes tratamentos e momentos experimentais em tetos provenientes de fêmeas bovinas

\begin{tabular}{lcccc}
\hline Tratamentos & M 0 & M 10' & M 30' & M 60' \\
\hline Óxido de zinco & $4,95 \times 10^{\prime} \mathrm{ABc}$ & $1,08 \times 10^{3} \mathrm{Bb}$ & $0,44 \times 10^{3} \mathrm{Ba}$ & $0,30 \times 10^{3} \mathrm{Ba}$ \\
Controle óxido de zinco & $0,84 \times 10^{3 \mathrm{Ac}}$ & $0,27 \times 10^{3 \mathrm{ABb}}$ & $0,05 \times 10^{\mathrm{ABb}}$ & $0,03 \times 10^{3 \mathrm{Aa}}$ \\
Nitrato de prata & $11,3 \times 10^{3 \mathrm{Bc}}$ & $0,12 \times 10^{3 \mathrm{Ab}}$ & $0,03 \times 10^{3 \mathrm{Aa}}$ & $0,03 \times 10^{3 \mathrm{Aa}}$ \\
Controle nitrato de prata & $2,14 \times 10^{3 \mathrm{ABc}}$ & $1,18 \times 10^{3 \mathrm{Bc}}$ & $0,23 \times 10^{3 \mathrm{ABb}}$ & $0,13 \times 10^{3 \mathrm{ABa}}$
\end{tabular}

Para cada momento, valores seguidos por letras minúsculas iguais não diferem entre si $(\mathrm{P}>0,05)$. Para cada tratamento, valores seguidos por letras maiúsculas iguais não diferem entre si $(\mathrm{P}>0,05)$. 
tocante ao atendimento de outros critérios que devem ser atendidos para finalmente poderem ser utilizados na desinfecção de tetos na rotina de ordenha de bovinos. Devem-se considerar fatores como eficácia sobre os agentes envolvidos na mastite; tempo de ação compatível ao manejo a que os animais são submetidos; e pouca suscetibilidade aos fatores intervenientes (presença de matéria orgânica, $\mathrm{pH}$ ), além disso, não deve possuir efeito colateral sobre a pele do animal e não deixar resíduos no leite (Schuch et al. 2008).

A maioria das informações disponíveis sobre a utilidade de prata como agente antimicrobiano é derivada da literatura médica humana, especialmente em relatórios publicados a respeito de lesões térmicas. A solução de nitrato de prata $(0,5 \%)$ é o fármaco de eleição para queimaduras, pois não interfere na proliferação epidérmica e possui propriedade antibacteriana contra Pseudomonas aeruginosa, Staphylococcus aureus e Escherichia coli (Moyer et al. 1965). É valido ressaltar que estas últimas duas espécies bacterianas são também consideradas agentes etiológicos da mastite. Mais aplicações tópicas dos compostos de prata são relatadas. 0 nitrato de prata é o tratamento preconizado para granulomas umbilicais de recém-nascidos, com a finalidade de reduzir o risco de infecção umbilical (Brodsgaard et al. 2015). Solução aquosa contendo sais de prata é instilada nos olhos de crianças recém-nascidas para evitar infecções oculares neonatais (Silver 2003). Nitrato de prata também foi utilizado na cauterização de estomatite aftosa em humanos (Özler 2014).

Na medicina veterinária, os compostos de prata são também utilizados em queimaduras, sendo administrados em equinos, animais de produção, em animais de companhia e até em espécies exóticas laboratoriais (Mcree 2015). A sulfadiazina de prata é o composto de eleição para o tratamento de queimaduras, quando comparado ao uso do nitrato de prata para esta mesma finalidade (Spinosa et al. 2006).

Em se tratando em tempo de ação, os íons de prata podem apresentar outra característica benéfica no sentido de prolongar a proteção do óstio após a ordenha. Faz-se referência a um estudo publicado em 2015 constatando que Pseudomonas aeruginosa mortas em solução de nitrato de prata, exerciam efeitos bactericidas quando foram colocadas em contato com outras bactérias vivas. Os pesquisadores descobriram que os íons de prata alojam-se nas membranas bacterianas abrindo caminho pelo seu interior e criando uma espécie de vesícula, de onde saem para o exterior, provocando a morte das bactérias existentes no meio extracelular (Wakshlak et al. 2015). Se essa propriedade for validada, a solução de nitrato de prata pode apresentar ação antimicrobiana prolongada, devido a um efeito residual das bactérias mortas aderidas a superfície do teto.

Relatos sobre toxidade da prata são controversos, existindo autores que sustentam a ausência de toxidade para células humanas (Silver 2003, Duran et al. 2007) enquanto outros são mais cautelosos enfatizando que existem efeitos adversos resultantes do uso de compostos de prata (Atiyeh et al. 2007, Gong et al. 2007). Caso a última afirmação venha a ser ratificada, sugere-se que a possível toxidade do nitrato de prata possa ser minimizada, ao reduzir sua con- centração nas soluções, ainda garantindo seu poder antibacteriano, já que conforme resultado deste experimento, a média obtida do ensaio de CBM com a solução de nitrato de prata foi extremante baixa, 19,20 $\mu \mathrm{g} / \mathrm{mL}$. A via de aplicação é outro fator a ser considerado na minimização dos efeitos tóxicos do nitrato de prata, considerando que a absorção dérmica da prata é pouco provável (Encyclopedia of Toxicology 2005a).

Alguns pontos são favoráveis à aplicação da solução do óxido de zinco como antissépticos mamários. A considerar a alta afinidade do óxido de zinco com Staphylococcus aureus (Soderberg et al. 1990, Sawai 2003) o principal patógeno da mastite (Brito et al. 2001, Taponen \& Pyörälä 2009). Outro fator importante é que o uso do óxido de zinco foi consolidado na farmacêutica humana com indicações para tratamentos de afecções dermatológicas, agindo como antisséptico, secativo e adstringente, através de formulações de cremes, loções, pomadas, pasta d'água, em altas concentrações (Batistuzzo et al. 2011, Anvisa 2012).

As aplicações do óxido de zinco exibidas acima, denotam sua baixa toxidade a células da epiderme, somado ao fato de que esse composto não é absorvido numa quantidade significativa quando aplicado à pele intacta (Encyclopedia of Toxicology 2005b).

Como visto, neste experimento foi possível afirmar que os antimicrobianos testados (soluções de óxido de zinco e nitrato de prata) foram eficazes na redução de $U F C / \mathrm{cm}^{2}$ na superfície do teto, e como supracitado, pode exercer efeito antimicrobiano sobre os principais agentes etiológicos da mastite.

Portanto, deve-se considerar o potencial destes antimicrobianos no controle e prevenção da mastite, tendo em vista o nível variado de graus de susceptibilidade e resistência, já documentados, dos desinfetantes rotineiramente utilizados na pecuária leiteira (Medeiros 2008, Ramalho et al. 2012).

\section{CONCLUSÃO}

Os antimicrobianos testados (soluções de óxido de zinco e de nitrato de prata) foram eficazes na redução de $\mathrm{UFC} / \mathrm{cm}^{2}$ na superfície do teto, podendo exercer efeito antimicrobiano sobre os principais agentes etiológicos da mastite, achados que caracterizam estas formulações como promissoras para antissepsia de tetos em procedimentos de ordenha. Logo, estudos complementares são necessários a fim de certificar o atendimento dos critérios preconizados para antissépticos de tetos, consolidando o óxido de zinco e o nitrato de prata como compostos alternativos para o controle e prevenção da mastite nos rebanhos leiteiros brasileiros.

\section{REFERÊNCIAS}

Amaral L.A., Isa H., Dias L.T., Junior O.D.R. \& Filho A.N. 2004. Avaliação da eficiência da desinfecção de teteiras e dos tetos no processo de ordenha mecânica de vacas. Pesq. Vet. Bras. 24:173-177.

Amornpitoksuk P., Suwanboon S., Sangkanu S., Sukhoom A., Wudtipan J., Srijan K. \& Kaewtaro S. 2001. Synthesis, photocatalytic and antibacterial activities of $\mathrm{ZnO}$ particles modified by diblock copolymer. Powder technology 212(3):432-438. 
Andrade U.V.C. 2010. Potencial antibacteriano do extrato hidrossolúvel de própolis obtido por hidrólise alcalina para a inibição de cultivos de staphylococcus aureus e higienização de pré e pós - imersão de tetos de vacas leiteiras. Tese de Doutorado. Disponível em< http://www.posalim. ufpr.br/Pesquisa/pdf/TeseURIEL.pdf> Acesso em 06 mai. 2016.

Anvisa 2012. Formulário nacional da farmacopeia brasileira. 2. ed. Brasília. Disponível em <http://www.anvisa.gov.br/hotsite/farmacopeiabrasileira/arquivos/2012/FNFB\%202_Revisao_2_COFAR_setembro_2012_ atual.pdf> Acesso em 24 jan. 2016.

Atiyeh B.S., Costagliola M. \& Hayek S.N. 2007. Effect of silver on burn wound infection control and healing: review of the literature. Burns. 33:139-148.

Batistuzzo J.A.O., Itaya M. \& Eto Y. 2011. Formulário médico farmacêutico. 4⿳亠丷厂 ed. Pharmabooks, São Paulo. 784p.

Brito J.R.F., Brito M.A.V.P. \& Vernequez B.R.S. 2000. Contagem bacteriana da superfície de tetas de vacas submetidas a diferentes processos de higienização, incluindo a ordenha manual com participação do bezerro para estimular a descida do leite. Ciência rural 30:847-850.

Brito M.A.V.P., Brito J.R.F., Silva M.A.S. \& Carmo R.A. 2001. Concentração mínima inibitória de dez antimicrobianos para amostra de Staphylococcus aureus isolados de infecção intramamária bovina. Arq. Bras. Med. Vet. Zootec. 53(5):531-537.

Brodsgaard A., Nielsen T., Molgaard U., Pryds O. \& Pedersen P. 2015. Treating umbilical granuloma with topical clobetasol propionate cream at home is as effective as treating it with topical silver nitrate in the clinic. Foundation Acta Paediatrica 104(2):174-177.

Castellano J.J., Shafii S.M., Ko F., Donate G., Wright T.E. \& Mannari R.J. 2007. Comparative evaluation of silver-containing antimicrobial dressings and drugs. Int. Wound J. 4(2):114-22.

CLSI 2015. Methods for dilution antimicrobial susceptibility tests for bacteria that grow aerobically. Clinical and Laboratory Standards Institute. Approved Standard, Tenth ed. CLSI document M07-A10. Wayne, PA.

Contreras A., Sierra D., Anchez A.S., Corrales J.C., Marco J.C., Paape M.J. \& Gonzalo C. 2007. Mastitis in small ruminants. Small Ruminant Research, 68:145-153.

Coser S.M., Lopes M.A. \& Costa G.M. 2012. Mastite bovina, controle e prevenção. Disponível em <http://livraria.editora.ufla.br/upload/boletim/tecnico/boletim-tecnico-93.pdf> Acesso em 17 jan. 2016.

Duran N., Marcarto P.D., Souza G.I.H., Alves O.L. \& Esposito E. 2007. Antibacterial effect of silver nanoparticles produced by fungal process on textile fabrics and their effluent treatment. J. Biomed Nanotechnol. 3:203-208.

Encyclopedia of Toxicology 2005a. Silver. Disponível em <http://www. sciencedirect.com/science/article/pii/B0123694000008784> Acesso em 09 mai. 2016.

Encyclopedia of Toxicology 2005b. Zinc oxide. 2. Disponível em <http:// www.sciencedirect.com/science/article/pii/B0123694000010267> Acesso em 13 jan. 2016.

Faccin A. 2013. Atividade antibacteriana in vitro e in vivo de Schinus terebinthifolius Raddi no controle da mastite bovina. Dissertação de Mestrado. Disponível em<http://repositorio.ufpel.edu.br/handle/123456789 /2489> Acesso em 05 jan. 2016.

Feltrin C.W. 2010. Síntese e propriedades do ZnO: correlação entre propriedades estruturais e atividade fotocatalítica. Dissertação de Mestrado. Disponível em <http://www.lume.ufrgs.br/bitstream/handle $/ 10183 / 27179 / 000764136$.pdf?sequence=1> Acesso em 09 mai. 2016.

Finger R.M. 2001. Fatores de riscos da higiene de vacas com elevado número de bactérias mesofílicas aeróbias no leite. Tese de Doutorado. Disponível em< http://alexandria.cpd.ufv.br:8000/teses/157445f.pdf> Acesso em 13 mai. 2016.

Fonseca L.F.L. \& Santos M.V. 2007. Estratégias de controle para mastite e melhoria na qualidade do leite. Manole, Barueri. 314p.

Fundação Banco do Brasil. 2010. Desenvolvimento regional sustentável. Bovinocultura de leite. Vol.1, 57p. Disponivel em <http://www.bb.com. br/docs/pub/inst/dwn/Vol1BovinoLeite.pdf> Acesso em 17 abr. 2017.
Gomes A.M., Pintado M.E. \& Malcata X. 2008. Conhecer a importância do leite na nutrição humana. Leite + I + D + T. 2:2-4.

Gong P., Li H., He X., Wang K., Hu J., Tan W., Zhang S. \& Yang X. 2007. Preparation and antibacterial activity of $\mathrm{Fe}_{3} \mathrm{O}_{4} \mathrm{Ag}$ nanoparticles. Nanotechnology 18:604-11.

IBGE 2014. Produção da pecuária municipal. Disponível em <http:// biblioteca.ibge.gov.br/visualizacao/periodicos/84/ppm_2014_v42_ br.pdf> Acesso em 11 mai. 2016.

Ip M., Lui S.L., Poon V.K.M., Lung I. \& Burd A. 2006. Antimicrobial activities of silver dressings: an in vitro comparison. Journal of Medical Microbiology 55:59-63.

Krewer C.C., Amanso E.S., Gouveia G.V., Souza R.L., Costa M.M. \& Mota R.A. 2014. Resistance to antimicrobials and biofilm formation in Staphylococcus spp. isolated from bovine mastitis in the Northeast of Brazil. Trop Anim Health Prod. 47:511-518.

Liedtke J. \& Vahjen W. 2012. In vitro antibacterial activity of zinc oxide on a broad range of reference strains of intestinal origin. Veterinary Microbiology, 160:251-255.

Langoni H. 2013. Qualidade do leite: utopia sem um programa sério de monitoramento da ocorrência de mastite bovina. Pesq. Vet. Bras. 33(5): 620-626.

Lansdown A.B.G. 2002. Silver I: its antibacterial properties and mechanism of action. J Wound Care. 11:125-38.

Mcree A.E. 2015. Therapeutic review: silver. Journal of Exotic Pet Medicine 24:240-244.

Medeiros E.S. 2008. Perfil da sensibilidade in vitro dos Staphylococcus ssp. frente a antimicrobianos e desinfetantes utilizados no controle da mastite bovina. Dissertação de Mestrado. Disponível em $<$ http://200.17.137.108/tde_busca/arquivo.php?codArquivo=862> Acesso em 9 jan. 2016.

Moyer C.A., Brentano L., Gravens D.L., Margraf H.W. \& Monafo W.W. 1965. Treatment of Large Human Burns With 0.5\% Silver Nitrate Solution. Arch Surg. 90:62-67.

Özler G.S. 2014. Silver nitrate cauterization: A treatment option for aphthous Stomatitis. Journal of Cranio-Maxillo-Facial Surgery, 42(5):281283.

Pedrini S.C.B. \& Margatho L.F.F. 2003. Sensibilidade de microrganismos patogênicos isolados de casos de mastite clínica em bovinos frente a diferentes tipos de desinfetantes. Arqs Inst. Biológico. 70(4):391-395.

Percival S.L., Bowler P.G. \& Russell D. 2005. Bacterial resistance to silver in wound care. J. Hosp. Infect. 60:1-7.

Quinn P.J., Markey B.K., Carter M.E., Donnelly W.J. \& Leonard F.C. 2005. Microbiologia veterinária e doenças infecciosas. Artmed, Porto Alegre. $512 \mathrm{p}$.

Radostits O.M., Gay C.C., Blood D.C. \& Hinchcliff K.W. 2002. Clínica Veterinária. Um tratado de doenças dos bovinos, ovinos, suínos, caprinos e eqüinos. Guanabara Koogan, Rio de Janeiro. 1737p.

Rai M., Yadav A. \& Gade A. 2009. Silver nanoparticles as a new generation of antimicrobials. Biotechnology Advances. 27:76-83.

Ramalho A.C., Soares K.D.A., Silva D.F., Barros M.R.C., Júnior J.W.P., Oliveira J. M.B., Mota R.A. \& Medeiros E.S. 2012. Eficácia in vitro de desinfetantes comerciais utilizados no pré e pós-dipping frente a Staphylococcus spp. isolados em rebanhos leiteiros. Pesq. Vet. Bras. 32(12):1285-1288.

Rocha D.P., Pinto G.F., Ruggiero R., Oliveira C.A. \& Guerra W. 2011. Coordenação de metais a antibióticos como uma estratégia de combate à resistência bacteriana. Quim. Nova. 34:111-118.

Sarkar S., Jana A.D., Samanta S.K. \& Mostafa G. 2007. Facile synthesis of silver nano particles with highly efficient anti-microbial property. Polyhedron. 26:4419-4426.

Sawai J., Igarashi H., Hashimoto A., Kokugan T. \& Shimizu M. 1995. Evaluation of growth inhibitory effect of ceramics powder slurry on bacteria by conductance method. Journal of the Ceramic Society of Japan 28(3):288293.

Sawai J., Shoji S., Igarashi H., Hashimoto A., Kokugan T. \& Shimizu M. 1998. Hydrogen peroxide as an antibacterial factor in zinc oxide powder slurry. Journal of Fermentation and Bioengineering 86:521-522. 
Sawai J. 2003. Quantitative evaluation of antibacterial activities of metallic oxide powders $(\mathrm{ZnO}, \mathrm{MgO}$ and $\mathrm{CaO}$ ) by conductimetric assay. J Microbiol. Methods, 54(2):177-182.

Schuch L.F.D., Wiest J.M., Coimbra H.S., Prestes L.S., Toni L. \& Lemos J.S. 2008. Cinética da atividade Antibacteriana in vitro de extratos naturais frente a micro-organismos relacionados a mastite bovina. Ciência Animal Brasileira 9:161-169.

Silva N., Junqueira V.C.A., Silveira N.F.A., Taniwaki M.H., Santos R.F.S. \& Gomes R.A.R. 2007. Manual de métodos de análise microbiológica de alimentos. Livraria Varela, São Paulo. 552p.

Silver S. 1996. Bacterial resistances to toxic metal ions - a review. Gene. 179:9-19.

Silver S. 2003. Bacterial silver resistance: molecular biology and uses and misuses of silver compounds. Fems. Microbiol. Rev. 27(2-3):341-353.

Simões T.V.M.D. \& Oliveira A.A. 2012. Mastite bovina: considerações e impactos econômicos. 1. ed. Embrapa Tabuleiros Costeiros. Disponível em< http://www.cpatc.embrapa.br/publicacoes_2012/doc_170.pdf> Acesso em 8 mai. 2016
Soderberg T.A., Sunzel B., Holm S., Elmros T., Hallmans G. \& Sjöberg S. 1990. Antibacterial effect of zinc oxide in vitro. Scandinavian Journal of Plastic and Reconstructive Surgery and Hand Surgery, 24(3):193-197.

Spinosa H.S., Gorniak S.L. \& Bernardi M.M. 2006. Farmacologia Aplicada à Medicina Veterinária. Guanabara Koogan, Rio de Janeiro. 897p.

Taponen S. \& Pyorala S. 2009. Coagulase-negative staphylococci as cause of bovine mastitis - not so different from Staphylococcus aureus? Veterinary Microbiology 134[2]:29-36.

Trop M., Novak M. \& Rodl S. 2006. Silver-coated dressing acticoat caused raised liver enzymes and argyria-like symptoms in burn patient. J. Trauma. 60:648-652.

Wakshlak R.B.K., Pedahzur R. \& Avnir D. 2015. Antibacterial activity of silver-killed bacteria: the "zombies" effect. Scientific Reports. 5[9555]:1-9.

Yokoia E. 2010. Controle de infecções intramamárias no gado leiteiro usando as propriedades antibacterianas e cicatrizantes do muco de escargots Achatina sp. no pré e pós-dipping. Dissertação de Mestrado. Disponível em < www.teses.usp.br/teses/disponiveis/10/10135/tde.../ Eugenio_Yokoya.pdf> Acesso em 12 jan. 2016. 